\title{
Serum potassium levels predict blood pressure response to aldosterone antagonists in resistant hypertension
}

\author{
Gadi Shlomai ${ }^{1,2}$, Tal Sella ${ }^{2}$, Yehonatan Sharabi, Avshalom Leibowitz and Ehud Grossman
}

The objective of this study was to identify factors associated with the blood pressure (BP) response to spironolactonealdosterone receptor antagonist as an add-on therapy in patients with resistant hypertension (HTN). We retrospectively reviewed the data of subjects with resistant HTN who were treated with add-on spironolactone in a large HTN clinic. A paired Student's $t$-test was used to assess the differences between the BP values before and during spironolactone administration, and multivariate analysis was used to assess the predictors of a satisfactory BP response (a decrease in systolic BP $>10 \%$ ). We analyzed the data of 48 hypertensive participants. The add-on spironolactone therapy had a significant BP-lowering effect in both systolic and diastolic BP values $\left(P<0.01\right.$ for both). Baseline serum potassium levels of $<4.5 \mathrm{mEq} \mathrm{I}^{-1}$ were associated with a satisfactory BP response $(\boldsymbol{P}<0.01)$. Furthermore, every decrement of $1 \mathrm{mEqI}^{-1}$ of serum potassium was independently associated with a fivefold higher rate of achieving a satisfactory BP response to spironolactone therapy $(P=0.024)$. Additional factors independently associated with an improved systolic BP response were old age $(P=0.033)$, body mass index $(P=0.033)$ and high baseline systolic BP $(P=0.004)$. Our results support the use of add-on spironolactone therapy in patients with resistant HTN who are elderly and obese and have high systolic BP and serum potassium levels $<4.5 \mathrm{mEq} \mathrm{I}^{-1}$. Hypertension Research (2014) 37, 1037-1041; doi:10.1038/hr.2014.77; published online 27 March 2014

Keywords: aldosterone receptor antagonist; potassium; resistant hypertension

\section{INTRODUCTION}

Arterial hypertension (HTN) constitutes a pivotal, modifiable cardiovascular risk factor for stroke, coronary artery disease, heart failure and end-stage renal disease. ${ }^{1}$ Antihypertensive therapy profoundly reduces the risk of HTN-related morbidity and mortality. ${ }^{2}$ Notably, regardless of the agent employed, monotherapy fails to adequately control blood pressure (BP) in $>70 \%$ of patients. ${ }^{3}$ Resistant HTN is defined as not at goal BP (systolic BP $<140 \mathrm{~mm} \mathrm{Hg}$ and diastolic BP $90 \mathrm{~mm} \mathrm{Hg}$ ) despite the use of at least three antihypertensive medications of different drug classes at optimal doses, usually including a diuretic. ${ }^{4}$

Spironolactone is a nonselective aldosterone receptor antagonist and a potassium-sparing diuretic. The beneficial effect of administering spironolactone to lower BP has been previously demonstrated in patients with uncontrolled and true resistant HTN, even if they had essential HTN. ${ }^{5-13}$ These findings have been reflected in the British Hypertension Society guidelines since 2004, ${ }^{2,14}$ which recommend spironolactone as fourth-line therapy when BP is uncontrolled by other pharmacological measures.
The BP-lowering capacity of spironolactone is well established. However, it is unclear who will favorably respond to this medication. Because treatment with spironolactone is not well tolerated, particularly in males, and may lead to hyperkalemia and renal deterioration, it is important to identify patients in whom spironolactone therapy will be highly effective. Several trials have shown that the BP-lowering effect of spironolactone correlates with a higher baseline BP; 7,15 however, other studies have failed to demonstrate such an association. ${ }^{15,16}$ The baseline serum potassium levels, plasma renin activity and aldosterone levels have also been previously suggested to be potential predictors for BP response to spironolactone; however, the published data thus far show conflicting results. ${ }^{5-7,9,11,17,18}$ Previously described factors that are likely associated with better BP response include body mass index, ${ }^{15}$ waist circumference and lower aortic stiffness. 6

The objectives of this study were to evaluate the BP-lowering effect of spironolactone, as an add-on therapy, in patients with uncontrolled and resistant HTN and to identify potential factors that may predict a favorable BP response to spironolactone therapy.

\footnotetext{
Department of Internal Medicine D and Hypertension Unit, The Chaim Sheba Medical Center, Tel-Hashomer Sackler Faculty of Medicine, Tel-Aviv University, Tel-Aviv, Israel

${ }^{1}$ The Dr Pinchas Borenstein Talpiot Medical Leadership Program 2013.

${ }^{2}$ These authors contributed equally to this work.

Correspondence: Professor E Grossman, Department of Internal Medicine D and Hypertension Unit, The Chaim Sheba Medical Center, Tel-Hashomer Sackler Faculty of Medicine, Tel-Aviv University, Tel-Aviv 52621, Israel.

E-mail: grosse@post.tau.ac.il

Received 2 November 2013; revised 13 February 2014; accepted 13 February 2014; published online 27 March 2014
} 


\section{METHODS}

\section{Patients}

This retrospective study was conducted in the HTN clinic of the Chaim Sheba Medical Center, Tel Hashomer, Israel. We reviewed the charts of 4105 hypertensive patients who were treated at our HTN clinic between 1 January 2003 and 31 December 2011. We identified those who initiated spironolactone therapy during the course of the treatment. We included in this analysis only patients with essential HTN, who were on nonpharmacological measures and were treated with two or more antihypertensive medications, before spironolactone therapy was administered. The participants continued their prior antihypertensive regimen, and their laboratory and demographic data and BP levels were recorded before and after the initiation of spironolactone treatment. According to standard clinic protocol, all of the patients were screened for secondary HTN during their initial visit. Consequently, those with suspected secondary HTN were excluded from the current analysis. Follow-up visits ranged from 2 weeks to 2 years.

\section{Data collection}

The demographic and clinical characteristics were recorded for each subject. Co-morbidities were self-reported. All of the patients underwent laboratory evaluations including serum glucose, renal function and electrolyte assessments before spironolactone initiation.

Blood pressure was measured according to the American Heart Association guidelines, using a mercury sphygmomanometer. The mean of two measurements, obtained by trained physicians after the patient had rested for $5 \mathrm{~min}$ in the sitting position, was recorded during every visit. For study purposes, the $\mathrm{BP}$ values were collected and measured on the following two specific dates: the date on which spironolactone therapy was initiated and on the first subsequent follow-up visit.

\section{Statistical analysis}

All of the statistical analyses were conducted using a standard statistical software package (SPSS 17.0, SPSS, Chicago, IL, USA). The results are presented as the mean values with standard deviations for normally distributed continuous variables and as medians for variables with asymmetric distributions. Consistent with previous publications, ${ }^{6}$ the $\mathrm{BP}$ response to spironolactone was also evaluated as the percentage change from baseline values [(first $\mathrm{BP}$ - second $\mathrm{BP} /$ first $\mathrm{BP}) \times 100$ ] and was considered to be satisfactory if the value was greater than $10 \%$. Paired Student's $t$-tests were used to assess the differences between the office BP levels before and after spironolactone administration. The chi-square test for categorical variables and the unpaired $t$-test or Mann-Whitney test for continuous variables were performed to determine significant differences in baseline characteristics between satisfactory and unsatisfactory responders. The same tests were applied for additional comparisons of the study population stratified by the baseline potassium level $\left(\geqslant 4.5\right.$ or $<4.5 \mathrm{mEq}^{-1}$ ). To identify the predictors of a satisfactory BP response, a multivariate logistic regression was performed with adjustment for variables if a significant difference was found between the subgroups. Two models were used: baseline potassium concentration was defined as a continuous variable in the first model and as a categorical variable ( $<4.5$ vs $\geqslant 4.5 \mathrm{mEql}^{-1}$ ) in the second model. $P<0.05$ was considered to be statistically significant.

\section{RESULTS}

\section{Patient characteristics}

We identified 63 patients who were eligible for inclusion in the study. The complete data for 48 patients included demographics, comorbidities and laboratory evaluation. Of the 48 hypertensive patients included in our study, the majority of the patients were males, tended to be overweight and were likely to have a medical history of diabetes and coronary heart disease (Table 1). The subjects were treated using various antihypertensive drug classes, mainly diuretics and reninangiotensin axis blockers. The majority $(87.5 \%)$ of the patients met the definition of resistant HTN, using at least three antihypertensive agents, including a diuretic. The median number of medications used
Table 1 Population baseline characteristics

\begin{tabular}{|c|c|}
\hline Characteristics & Values \\
\hline$N$ & 48 \\
\hline Sex (male)-n (\%) & $29(60.4)$ \\
\hline Age (years)—mean (s.d.) & $65.4(11)$ \\
\hline BMI ( $\left.\mathrm{kg} \mathrm{m}^{-2}\right)$-mean (s.d.) & $28.3(4.9)$ \\
\hline \multicolumn{2}{|l|}{ Pre-spironolactone BP-mean (s.d.) } \\
\hline Systolic BP, mm Hg & $156(23)$ \\
\hline Diastolic BP, mm Hg & $87(16)$ \\
\hline \multicolumn{2}{|l|}{ Comorbidities-n (\%) } \\
\hline Diabetes & $16(33.3)$ \\
\hline Hyperlipidemia & $1(2.1)$ \\
\hline Ischemic heart disease & 11 (22.9) \\
\hline Cerebral vascular disease & $0(0.0)$ \\
\hline Smoking & $3(6.3)$ \\
\hline Antihypertensive drugs-median (s.d.) & $4.0(1.0)$ \\
\hline \multicolumn{2}{|l|}{ Antihypertensive drugs, number- $\mathrm{n}(\%)$} \\
\hline 2 & $6(12.5)$ \\
\hline 3 & $10(20.8)$ \\
\hline 4 & $25(52.1)$ \\
\hline 5 & $7(14.6)$ \\
\hline \multicolumn{2}{|l|}{ Antihypertensive drugs, type - $\mathrm{n}(\%)$} \\
\hline Beta blocker & $40(83.3)$ \\
\hline Calcium channel blocker & $41(85.4)$ \\
\hline ACE inhibitor/AR blocker & $42(87.5)$ \\
\hline Diuretic & $44(91.7)$ \\
\hline Alpha blocker & $10(20.8)$ \\
\hline \multicolumn{2}{|l|}{ Laboratory values_median (s.d.) } \\
\hline Sodium, $\mathrm{mEq} \mathrm{I}^{-1}$ & $140(3.35)$ \\
\hline Potassium, $\mathrm{mEq} \mathrm{I}^{-1}$ & $4.3(0.79)$ \\
\hline Creatinine, $\mathrm{mgdl}^{-1}$ & $1.08(0.24)$ \\
\hline Urea, $\mathrm{mg} \mathrm{dl}^{-1}$ & $40(16.3)$ \\
\hline \multicolumn{2}{|l|}{ Target organ damage - n/tested (\%) } \\
\hline Left ventricular hypertrophy & 19/27 (70.4 \\
\hline Microalbuminuria & $8 / 26(30.8)$ \\
\hline
\end{tabular}

Abbreviations: ACE, angiotensin-converting enzyme; AR, angiotensin receptor; BMI, body mass index; BP, blood pressure.

by patients in our study population was 4 (Table 1 ). Left ventricular hypertrophy was observed in $70.4 \%$ of the patients tested, and microalbuminuria was observed in $30.8 \%$ of the patients tested (Table 1).

\section{Patients' baseline characteristics stratified by systolic blood pressure response}

In the entire group, the addition of spironolactone (mean dose, $20.6 \pm 13.6 \mathrm{mg}$ per day) decreased systolic BP (SBP) from $156 \pm 23$ to $147 \pm 21 \mathrm{~mm} \mathrm{Hg}$ and diastolic BP (DBP) from $87 \pm 16$ to $78 \pm 18 \mathrm{~mm}$ $\mathrm{Hg}(P<0.01$ for both) (Figure 1). Seventeen patients (35\%) exhibited satisfactory SBP response ( $>10 \%$ BP reduction). Those patients with satisfactory SBP responses had higher baseline SBP levels and lower serum potassium levels than those without satisfactory responses (Table 2). Other baseline characteristics and laboratory parameters were similar in those with and without satisfactory SBP responses 

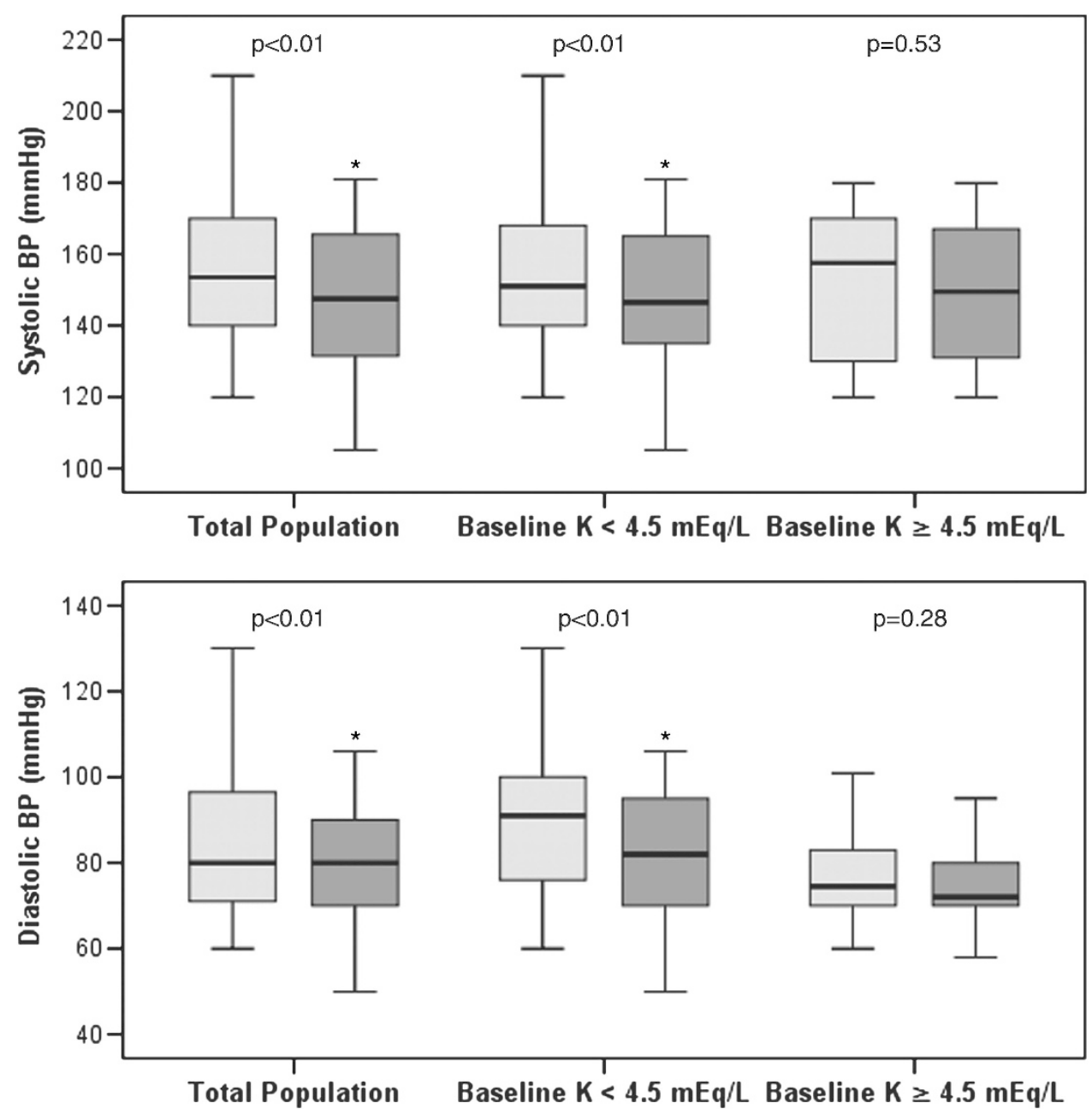

Figure 1 Systolic and diastolic blood pressure values before (light boxes) and after (dark boxes) spironolactone commencement. The blood pressure values are described for the entire study population and stratified by a serum potassium level of $4.5 \mathrm{mEqI} \mathrm{I}^{-1}$. ${ }^{*} P$ values derived from paired $t$-test comparisons of blood pressures before and after spironolactone therapy.

(Table 2). The pretreatment medications did not predict a satisfactory response. Notably, treatment with angiotensin-converting enzyme inhibitors/angiotensin receptor blockers and beta-blockers showed a trend towards an association with a lesser SBP response to spironolactone therapy (Table 2).

The effect of spironolactone on blood pressure stratified by baseline serum potassium levels

Baseline potassium levels of $<4.5 \mathrm{mEql}^{-1}$ were recorded in 26 patients. An add-on spironolactone therapy decreased systolic and diastolic BP significantly only in patients with baseline potassium levels of $<4.5 \mathrm{mEql}^{-1}(161 \pm 24$ to $146 \pm 21 \mathrm{~mm} \mathrm{Hg}$, and $91 \pm 20$ to $79 \pm 21 \mathrm{~mm} \mathrm{Hg}$, respectively; $P<0.01$ for both) (Figure 1).

A multivariate analysis showed that every $1 \mathrm{mEq}$ decrement in serum potassium was independently associated with a fivefold higher rate of achieving satisfactory SBP response $(P=0.024)$ (Table 3$)$. The use of a categorical multivariable model demonstrated that a baseline potassium level of $<4.5 \mathrm{mEql}^{-1}$ was associated with a 12-fold increase in the rate of achieving satisfactory SBP response $(P=0.017)$ (Table 3$)$. Additional factors independently associated with satisfactory SBP response are older age $(P=0.033)$, increased body mass index $(P=0.033)$ and higher baseline SBP values $(P=0.004)$ (Table 3).

\section{DISCUSSION}

This study corroborates the role of spironolactone treatment in the management algorithm of patients with uncontrolled and resistant HTN. Our findings suggest that lower baseline potassium levels, higher pre-treatment SBP values, old age and obesity are associated with an improved SBP response to spironolactone treatment.

Numerous trials have previously demonstrated the beneficial effect of spironolactone therapy for controlling BP in patients with resistant HTN ${ }^{5-13}$ Notably, the degree of BP reduction observed in our study was modest, albeit significant, compared with the majority of previous trials. This outcome could be attributed, in part, to the severity of HTN in our cohort because many patients were treated with four antihypertensive medications before spironolactone initiation. Another plausible explanation is that, despite having resistant HTN, our population had lower baseline SBP values compared with several other studies in which BP reduction was more prominent. ${ }^{6,8,9,11}$ It is also likely that the baseline serum potassium levels, which are associated with BP response to spironolactone, were relatively high because only 26 patients had 
Table 2 Baseline characteristics by adequate ( $>10 \%$ ) systolic blood pressure response to spironolactone

\begin{tabular}{|c|c|c|c|}
\hline \multirow[b]{2}{*}{ Variable } & \multicolumn{3}{|c|}{$S B P$ response } \\
\hline & $>10 \%$ & $\leqslant 10 \%$ & P-value \\
\hline$n$ & 17 & 31 & \\
\hline Sex (male)- $n, \%$ & $12(70.6)$ & $14(45.2)$ & 0.286 \\
\hline Age (years)—mean (s.d.) & $65.2(13.1)$ & $65.5(9.9)$ & 0.926 \\
\hline BMI $\left(\mathrm{kg} \mathrm{m}^{-2}\right.$ )—mean (s.d.) & $29.1(4.9)$ & $27.9(4.9)$ & 0.445 \\
\hline \multicolumn{4}{|l|}{ Pre-spironolactone BP-mean (s.d.) } \\
\hline Systolic BP, mm Hg & $168(25)$ & $150(19)$ & 0.006 \\
\hline Diastolic BP, mm Hg & $92(25)$ & $82(12)$ & 0.152 \\
\hline \multicolumn{4}{|l|}{ Comorbidities - n (\%) } \\
\hline Diabetes & $7(41.2)$ & $9(29.0)$ & 0.393 \\
\hline Hyperlipidemia & $1(5.9)$ & $0(0.0)$ & 0.172 \\
\hline Ischemic heart disease & $2(11.8)$ & $9(29.0)$ & 0.173 \\
\hline Cerebral vascular disease & $0(0.0)$ & $0(0.0)$ & - \\
\hline Smoking & $1(5.9)$ & $2(6.5)$ & 0.938 \\
\hline Antihypertensive drugs—median (s.d.) & $3.5(1.0)$ & $4.0(1.0)$ & 0.205 \\
\hline \multicolumn{4}{|l|}{ Antihypertensive drugs- $\mathrm{n}(\%)$} \\
\hline Beta blocker & $12(70.6)$ & $28(90.3)$ & 0.079 \\
\hline Calcium channel blocker & $14(82.4)$ & $27(87.1)$ & 0.656 \\
\hline ACE inhibitor/AR blocker & $13(76.5)$ & $29(93.5)$ & 0.087 \\
\hline Diuretic & $15(88.2)$ & $29(93.5)$ & 0.524 \\
\hline Alpha blocker & $5(29.4)$ & $5(16.1)$ & 0.278 \\
\hline \multicolumn{4}{|l|}{ Laboratory values_median (s.d.) } \\
\hline Sodium, mEqI-1 & $140(3.0)$ & $140(3.6)$ & 0.786 \\
\hline Potassium, $\mathrm{mEq} \mathrm{I}^{-1}$ & $3.95(0.6)$ & $4.55(0.8)$ & 0.037 \\
\hline Creatinine, $\mathrm{mg} \mathrm{dl}^{-1}$ & $0.98(0.3)$ & $1.1(0.2)$ & 0.398 \\
\hline Urea, $\mathrm{mg} \mathrm{dl}^{-1}$ & $34(16.8)$ & $41(16.0)$ & 0.317 \\
\hline \multicolumn{4}{|l|}{ Target organ damage $-\mathrm{n} /$ tested (\%) } \\
\hline Left ventricular hypertrophy & 9/11 (81.8) & $10 / 16(62.5)$ & 0.280 \\
\hline Microalbuminuria & $5 / 11(45.5)$ & $3 / 15(20.0)$ & 0.165 \\
\hline
\end{tabular}

Abbreviations: ACE, angiotensin-converting enzyme; AR, angiotensin receptor; BMI, body mass index; $\mathrm{BP}$, blood pressure; SBP, systolic blood pressure.

levels $<4.5 \mathrm{mEql}^{-1}$; therefore, the response in the entire group was only modest. Satisfactory SBP reduction was achieved in only $35 \%$ of the patients; however, it is noteworthy that even those without a satisfactory BP response exhibited some degree of decrease in SBP because the overall effect of an add-on spironolactone therapy was significant.

The pathophysiology of resistant HTN is usually multifactorial, including poor patient adherence, concomitant renal disease or secondary etiologies, vascular stiffness and aldosterone breakthrough. ${ }^{9,19}$ Although the primary mechanism underlying the effect of spironolactone on BP reduction is likely natriuresis and diuresis, aldosterone blockade plays a significant role in vascular stiffness modulation, sympathetic tone attenuation ${ }^{20}$ and endothelial function protection. ${ }^{21}$ These extra-renal effects could mediate the additional BP-lowering capacity of spironolactone therapy among patients who are already receiving intense treatment with various types of antihypertensive medications.

This study demonstrates that the BP response to spironolactone depends on serum potassium levels. The lower the baseline potassium
Table 3 Multivariate logistic regression for adequate ( $>10 \%$ ) systolic blood pressure response to spironolactone with potassium as a continuous (a) and a categorical (b) variable

\begin{tabular}{|c|c|c|c|}
\hline Variable & $O R$ & $95 \% \mathrm{Cl}$ & P-value \\
\hline \multicolumn{4}{|l|}{ (a) } \\
\hline \multicolumn{4}{|l|}{ Gender } \\
\hline Male & 1 & - & - \\
\hline Female & 0.29 & $0.04-1.88$ & 0.196 \\
\hline \multicolumn{4}{|l|}{ Age } \\
\hline 1-year increment & 1.16 & $1.03-1.30$ & 0.033 \\
\hline \multicolumn{4}{|l|}{$B M I$} \\
\hline $1 \mathrm{~kg} \mathrm{~m}^{-2}$ increment & 1.29 & $1.02-1.62$ & 0.033 \\
\hline \multicolumn{4}{|l|}{ K } \\
\hline $1 \mathrm{mEq} \mathrm{I}^{-1}$ decrement & 5.00 & $1.23-20.00$ & 0.024 \\
\hline \multicolumn{4}{|l|}{ Systolic BP } \\
\hline $1 \mathrm{~mm} \mathrm{Hg}$ increment & 1.08 & $1.03-1.14$ & 0.004 \\
\hline \multicolumn{4}{|l|}{ (b) } \\
\hline \multicolumn{4}{|l|}{ Gender } \\
\hline Male & 1 & - & - \\
\hline Female & 0.21 & $0.03-1.62$ & 0.134 \\
\hline \multicolumn{4}{|l|}{ Age } \\
\hline 1-year increment & 1.17 & $1.02-1.34$ & 0.023 \\
\hline \multicolumn{4}{|l|}{$B M I$} \\
\hline $1 \mathrm{~kg} \mathrm{~m}^{-2}$ increment & 1.3 & $1.01-1.69$ & 0.045 \\
\hline \multicolumn{4}{|l|}{$K$} \\
\hline$>4.5 \mathrm{mEqI}^{-1}$ & 1 & - & - \\
\hline$<4.5 \mathrm{mEq} \mathrm{I}^{-1}$ & 12.13 & $1.57-93.61$ & 0.017 \\
\hline \multicolumn{4}{|l|}{ Systolic BP } \\
\hline $1 \mathrm{~mm} \mathrm{Hg}$ increment & 1.07 & $1.02-1.13$ & 0.005 \\
\hline
\end{tabular}

Abbreviations: $\mathrm{BMI}$, body mass index; $\mathrm{BP}$, blood pressure; $\mathrm{K}$, potassium.

levels, the better the BP reduction. We have previously shown that pretreatment serum potassium levels $<4 \mathrm{mEql}^{-1}$ were associated with a greater BP reduction. ${ }^{11}$ de Souza et al. ${ }^{6}$ have also demonstrated that lower serum potassium levels were independently correlated with decreased SBP. However, other authors have failed to establish such an association. ${ }^{7}$ In the present study, we showed a remarkable BP decrease following an add-on spironolactone therapy in patients with serum potassium levels $<4.5 \mathrm{mEq}^{-1}$. Our findings concur with the most recent British guideline recommendations, which support the use of spironolactone for resistant HTN treatment if serum potassium levels are $<4.5 \mathrm{mEql}^{-1}$.

Contrary to traditional teaching, hypokalemia in hypertensive patients is not sine qua non for primary hyperaldosteronism. In the Primary Aldosteronism Prevalence in hYpertension Study (PAPY), the prevalence of primary hyperaldosteronism among newly diagnosed hypertensive patients was $11.2 \%{ }^{22}$ We believe that in our study $<5 \%$ of the patients could have primary aldosteronism because our standard clinic protocol for excluding secondary HTN includes measurements of plasma renin activity and aldosterone in patients with initial potassium levels $<4 \mathrm{mmoll}^{-1}$. Hypokalemia, even in the absence of primary hyperaldosteronism, may reflect elevated aldosterone levels. Many patients in our study had low serum potassium levels because of thiazide treatment. In these patients, spironolactone therapy was administered in addition to thiazide treatment. Relative baseline hypokalemia, regardless of the etiology, seems to be associated with better BP response to spironolactone therapy and appears to minimize the risk of hyperkalemia. Thus, it is prudent to continue thiazide treatment 
when spironolactone is added to the regimen of a patient with resistant HTN.

We have shown that higher baseline SBP levels are also associated with an improved response to add-on spironolactone therapy. The results of previous trials have been inconsistent. Several studies found that higher pretreatment $\mathrm{BP}$ values were associated with better $\mathrm{BP}$ reduction; ${ }^{7,15}$ however, other studies failed to establish such an association. $^{12}$

Our findings suggest that obesity is associated with an improved BP response to spironolactone. de Souza et al. ${ }^{6}$ showed that higher waist circumference predicted greater spironolactone-induced SBP reduction. The correlation between higher body mass index and improved BP reduction was also suggested by Khosla et al. ${ }^{15}$ The improved BP response to spironolactone in obese patients may be explained by the role of adipose tissue in the pathophysiology of mineralocorticoid excess. ${ }^{23-25}$ Adipose tissue has been shown to release angiotensinogen- and aldosterone-stimulating factors, thereby increasing aldosterone production by the adrenal gland. ${ }^{24}$

Old age was also associated with an improved BP response to spironolactone treatment. Age-related changes in salt sensitivity and in mineralocorticoid receptor machinery in the central nervous system might play a role in the improved response to spironolactone in old age.

Our study has several limitations. First, this retrospective study includes only patients who had all the required information in their medical files. Second, although the study group was small, we were able to identify the predictors of satisfactory responses to the add-on spironolactone therapy.

In conclusion, we presented data that support the use of add-on spironolactone treatment for patients with uncontrolled HTN. The most beneficial effect is evident among older patients with lower serum potassium levels, higher pretreatment SBP response and obesity. Additional prospective outcome studies are necessary to elucidate the role of spironolactone in preventing cardiovascular morbidity and mortality rates and to identify potential predictive factors for satisfactory BP responses to spironolactone therapy.

\section{CONFLICT OF INTEREST}

The authors declare no conflict of interest.

\section{ACKNOWLEDGEMENTS}

Dr Gadi Shomai was supported, in part, by a fellowship from the Dr Pinchas Borenstein Talpiot Medical Leadership Program 2013.

1 Lowe LP, Greenland P, Ruth KJ, Dyer AR, Stamler R, Stamler J. Impact of major cardiovascular disease risk factors, particularly in combination, on 22-year mortality in women and men. Arch lintern Med 1998; 158: 2007-2014.

2 Krause T, Lovibond K, Caulfield M, McCormack T, Williams B. Management of hypertension: summary of nice guidance. BMJ 2011; 343: d4891.
3 Dickerson JE, Hingorani AD, Ashby MJ, Palmer CR, Brown MJ. Optimisation of antihypertensive treatment by crossover rotation of four major classes. Lancet 1999; 353: 2008-2013.

4 Lloyd-Jones D, Adams RJ, Brown TM, Carnethon M, Dai S, De Simone G, Ferguson TB, Ford E, Furie K, Gillespie C, Go A, Greenlund K, Haase N, Hailpern S, Ho PM, Howard V, Kissela B, Kittner S, Lackland D, Lisabeth L, Marelli A, McDermott MM, Meigs J, Mozaffarian D, Mussolino M, Nichol G, Roger VL, Rosamond W, Sacco R, Sorlie P, Roger VL, Thom T, Wasserthiel-Smoller S, Wong ND, Wylie-Rosett J. Heart disease and stroke statistics-2010 update: a report from the American Heart Association. Circulation 2010; 121: e46-e215.

5 Chapman N, Dobson J, Wilson S, Dahlof B, Sever PS, Wedel H, Poulter NR. Effect of spironolactone on blood pressure in subjects with resistant hypertension. Hypertension 2007; 49: 839-845.

6 de Souza F, Muxfeldt E, Fiszman R, Salles G. Efficacy of spironolactone therapy in patients with true resistant hypertension. Hypertension 2010; 55: 147-152.

7 Jansen PM, Verdonk K, Imholz BP, Jan Danser AH, van den Meiracker AH. Long-term use of aldosterone-receptor antagonists in uncontrolled hypertension: a retrospective analysis. Int J Hypertens 2011; 2011: 368140.

8 Lane DA, Shah S, Beevers DG. Low-dose spironolactone in the management of resistant hypertension: a surveillance study. J Hypertens 2007; 25: 891-894.

9 Nishizaka MK, Zaman MA, Calhoun DA. Efficacy of low-dose spironolactone in subjects with resistant hypertension. Am J Hypertens 2003; 16: 925-930.

10 Ouzan J, Perault C, Lincoff AM, Carre E, Mertes M. The role of spironolactone in the treatment of patients with refractory hypertension. Am J Hypertens 2002; 15: 333-339.

11 Sharabi Y, Adler E, Shamis A, Nussinovitch N, Markovitz A, Grossman E. Efficacy of add-on aldosterone receptor blocker in uncontrolled hypertension. Am J Hypertens 2006; 19: 750-755.

12 Vaclavik J, Sedlak R, Jarkovsky J, Kocianova E, Taborsky M. Effect of spironolactone in patients with resistant arterial hypertension in relation to age and sex: insights from the aspirant trial. Biomedical Papers of the Medical Faculty of the University Palacky, Olomouc, Czechoslovakia, 2012

13 Vaclavik J, Sedlak R, Plachy M, Navratil K, Plasek J, Jarkovsky J, Vaclavik T, Husar R, Kocianova E, Taborsky M. Addition of spironolactone in patients with resistant arterial hypertension (aspirant): a randomized, double-blind, placebo-controlled trial. Hypertension 2011; 57: 1069-1075.

14 Williams B, Poulter NR, Brown MJ, Davis M, Mclnnes GT, Potter JF, Sever PS, Mc GTS. Guidelines for management of hypertension: report of the Fourth Working Party of The British Hypertension Society, 2004-BHS IV. J Hum Hypertens 2004; 18: 139-185.

15 Khosla N, Kalaitzidis R, Bakris GL. Predictors of hyperkalemia risk following hypertension control with aldosterone blockade. Am J Nephrol 2009. 30: 418-424.

16 Marrs JC. Spironolactone management of resistant hypertension. Ann Pharmacother 2010; 44: 1762-1769.

17 Mahmud A, Mahgoub M, Hall M, Feely J. Does aldosterone-to-renin ratio predict the antihypertensive effect of the aldosterone antagonist spironolactone? Am J Hypertens 2005; 18: 1631-1635.

18 Prisant LM, Krum H, Roniker B, Krause SL, Fakouhi K, He W. Can renin status predict the antihypertensive efficacy of eplerenone add-on therapy? J Clin Pharmacol 2003; 43: 1203-1210.

19 Staessen J, Lijnen P, Fagard R, Verschueren LJ, Amery A. Rise in plasma concentration of aldosterone during long-term angiotensin II suppression. J Endocrinol 1981; 91: 457-465.

20 Mulatero P, Rabbia F, Milan A, Paglieri C, Morello F, Chiandussi L, Veglio F. Drug effects on aldosterone/plasma renin activity ratio in primary aldosteronism. Hypertension 2002; 40: 897-902.

21 Rocha R, Funder JW. The pathophysiology of aldosterone in the cardiovascular system. Ann NY Acad Sci 2002; 970: 89-100.

22 Rossi GP, Bernini G, Caliumi C, Desideri G, Fabris B, Ferri C, Ganzaroli C, Giacchetti G, Letizia C, Maccario M, Mallamaci F, Mannelli M, Mattarello MJ, Moretti A, Palumbo G, Parenti G, Porteri E, Semplicini A, Rizzoni D, Rossi E, Boscaro M, Pessina AC, Mantero F. A prospective study of the prevalence of primary aldosteronism in 1,125 hypertensive patients. J Am Coll Cardiol 2006; 48: 2293-2300.

23 Goodfriend TL, Ball DL, Egan BM, Campbell WB, Nithipatikom K. Epoxy-keto derivative of linoleic acid stimulates aldosterone secretion. Hypertension 2004; 43: 358-363.

24 Lamounier-Zepter V, Ehrhart-Bornstein M. Fat tissue metabolism and adrenal steroid secretion. Curr Hyperten Rep 2006; 8: 30-34.

25 Pausova Z. From big fat cells to high blood pressure: a pathway to obesity-associated hypertension. Curr Opin Nephrol Hypertens 2006; 15: 173-178. 